MALLOMO: Journal of Community Service

https://jurnal.umsrappang.ac.id/mallomo/index

Vol 1, No 1, Desember 2020, pp 50-55

\title{
Pelatihan dan Pendampingan Guru dalam Mendesain Bahan Ajar Berbasis Digital di SMAN 10 Sidrap
}

\author{
Suleha ${ }^{1}$, Muhammad Hanafi ${ }^{2}$, Jumiati ${ }^{3}$, Nadira ${ }^{4}$ \\ 1,2,3 Pendidikan Bahasa Indonesia, Universitas Muhammadiyah Sidenreng Rappang \\ Email: sulehasurapati@gmail.com \\ ${ }^{4}$ Pendidikan Bahasa Inggris, Universitas Muhammadiyah Sidenreng Rappang
}

Abstract. This activity was carried out on 40 teachers of SMAN 10 Sidrao. The purpose of this activity is to provide training and assistance to target teachers in designing based teaching materials with the help of the Classroom Application. The methods used in this activity are preparation, implementation, and evaluation. Preparation includes administrative preparation and socialization. Implementation includes training and assistance for application operators. Evaluation is carried out after training and mentoring activities. This aims to measure the ability of teachers and the barriers that teachers experience. The results of this activity indicate that the teacher has been able to design digital-based teaching materials with the help of the Classroom application. In addition, this activity also produced handouts on how to operate the Classroom.

Abstrak. Kegiatan ini dilakukan pada guru SMAN 10 Sidrap yang berjumlah 40 orang. Tujuan kegiatan ini adalah untuk memberi pelatihan dan pendampingan kepada guru sasaran dalam mendesai bahan ajar berbasis dengan berbantuan Aplikasi Classroom. Metode yang digunakan dalam kegiatan ini berupa persiapan, pelaksanana, dan evaluasi. Persiapan meliputi persiapan admisitrasi dan sosialisasi. Pelaksanaan meliputi pelatihan dan pendampingan pengoperasi aplikasi. Evaluasi dilakukan setelah kegiatan pelatihan dan pendampingan. Hal ini bertujuan untuk mengukur kemampuan guru dan hambatan yang dialami guru. Hasil kegiatan ini menunjukkan bahwa guru telah mampu mendesain bahan ajar berbasis digital dengan bantuan aplikasi Classroom. Selain itu, kegiatan ini juga menghasilkan handout tentang cara pengoperasian Classroom. 
Keywords:

digital teaching

materials, classrooms,

training.

Kata Kunci:

bahan ajar digital,

classroom,

pelatihan.
Coresponden author:

Email: sulehasurapati@gmail.com

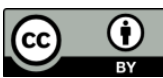

artikel dengan akses terbuka di bawah lisensi CC BY -4.0

\section{PENDAHULUAN}

Guru merupakan manusia pembelajar yang ikut berperan aktif dalam mencerdaskan anak bangsa. Oleh karena itu, guru dituntut untuk menjadi profesional di bidangnya. Guru yang profesional adalah guru yang mampu mengimplementasikan dengan efektif dan efisien prinsipprinsip pedagogik ke dalam rencana pembelajaran dan pelaksanaannya. Salah satu bentuk implementasi prinsip ini adalah pengembangan media dan bahan ajar (Zuriah, 2016). Penggunaan media dan bahan yang tepat dapat memotivasi peserta didik dan meningkatkan kemandiriannya dalam belajar (Alperi, 2019). Bahan ajar diartikan sebagai informasi, alat maupun teks diatur dengan sistematis,yang memuat kompetensi yang akan dikuasai peserta didik dan digunakan dalam proses pembelajaran dengan tujuan perencanaan dan penelaahan implementasi pembelajaran, misalnya buku pelajaran, modul, handout, LKS, model atau maket, bahan ajar audio, bahan ajar interaktif dsb. (Prastowo, 2013). Bahan ajar (modul) yang baik adalah bahan ajar yang mampu menggabungkan petunjuk belajar, berbagai jenis media, bahkan tautan daring yang dapat diakses peserta didik di mana saja (Yaumi, 2018).

Era revolusi industri 4.0 menuntut guru agar mampu mengembangkan bahan ajar berbasis digital. Mengingat bahwa peserta didik saat ini dikategorikan sebagai generasi digital native. Menurut Prensky, peserta didik dengan sebutan ini memiliki karakteristik yang terbiasa dengan struktur kognitif yang melompat-lompat, mampu melakukan beberapa kegiatan dalam waktu bersamaan, misalnya mendengarkan musik sambil membaca, dengan tetap dapat memahami bacaan yang dibacanya (Prensky dalam Faisal, 2020). Peserta didik ini sangat mahir dalam menggunakan perangkat digital dan senang meluangkan waktu bersama perangkat digitalnya. Sehingga, mereka menjadi leluasa belajar dan tertarik mempelajari bahan ajar yang dibagikan. Bahan ajar digital ini yang dapat diakses dengan menggunakan perangkat digital baik menggunakan smartphone maupun laptop/komputer.

Masalah yang banyak dialami guru adalah terbatasnya kemampuan dalam merencanakan, menyiapkan, dan membuat bahan ajar digital. Masalah lainnya adalah banyak guru yang kelabakan ketika diminta menyusun bahan ajar sendiri. Guru cenderung memilih untuk menggunakan bahan ajar buatan orang lain daripada buatan sendiri (Hamid, 2011; Daryanto 2012; Zuriyah 2016). Masalah ini juga dialami oleh guru-guru di SMAN 10 Sidrap. Fakta lain yang ditemukan adalah masih banyak guru yang mengandalkan buku paket sebagai sumber belajar dan metode ceramah sebagai metode mengajar. Namun, sekolah memiliki semangat yang tinggi untuk meningkatkan kualitas pembelajaran, baik dari segi proses maupun hasil belajar. Semangat ini perlu diapresiasi dengan memberikan pelatihan kepada guru. Pelatihan telah banyak membuktikan peningkatan kompetensi guru dalam proses belajar mengajar (Zuriah, 2016; Sab’ani, 2017; Faisal, 2020). Berdasarkan kondisi tersebut, penulis tertarik untuk membuat pelatihan dan pendampingan ini sebagai sarana untuk meningkatkan kompetensi guru dalam mengembangkan bahan ajar berbasis digital dengan bantuan Classroom. Classroom memberikan kemudahan dalam bidang pendidikan. Fitur yang disediakan sangat membantu guru dalam melaksanakan pembelajaran daring (Azhar, 2018). Aplikasi ini sangat cocok 


\section{2 | MALLOMO: Journal of Community Service}

digunakan terutama dalam masa pandemik ini. Aplikasi ini sangat mudah digunakan tidak memerlukan biaya dan peralatan mahal (Kurniawan, 2020).

\section{Metode}

Kegiatan dilaksanakan selama kurang lebih dua bulan. Sasaran kegiatan adalah guru di SMAN 10 Sidrap, Kabupaten Sidenreng Rappang sebanyak 40 orang. Metode yang dilakukan dalam kegiatan ini berupa sosialisasi, pelatihan, pendampingan, dan evaluasi. Kegiatan sosialisasi bertujuan untuk mengenalkan sekolah tentang desain bahan ajar berbasis digital sesuai dengan kebutuhan guru di sekolah. Pelatihan bertujuan untuk menyampaikan materi dan latihan tentang desain bahan ajar berbasis digital. Pendampingan bertujuan untuk mendampingi guru dalam membuat desain bahan ajarnya dan mengoperasikannya dalam pembelajaran di sekolah. Kegiatan pendampingan ini dilakukan oleh mahasiswa yang juga sedang magang di SMAN 10 Sidrap. Evaluasi bertujuan untuk mengetahui peningkatan kemampuan guru dan hambatan yang dialami guru selama kegiatan berlangsung. Alur kegiatan dapat dilihat secara jelas melalui bagan 1.

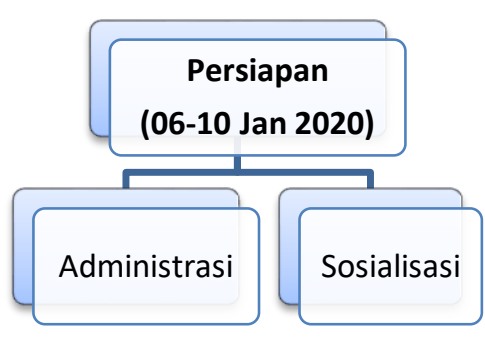

\section{Hasil Dan Pembahasan}

Hasil kegiatan ini berupa persiapan kegiatan, pelatihan dan pendampingan, serta evaluasi.

\section{a. Persiapan}

Kegiatan persiapan meliputi administrasi surat-menyurat dan sosialisasi yang dilakukan pada tanggal 6-10 Januari 2020. Sosialisasi ini bertujuan untuk menentukan jenis desain bahan ajar sesuai yang dibutuhkan guru. Kepala sekolah dan guru menyambut baik kegiatan ini. Melalui sosialisasi ini, sekolah dan pelaksana menentukan Classroom sebagai aplikasi yang digunakan dalam pelatihan.

\section{b. Pelatihan dan Pendampingan}

Pelatihan ini dilakukan dengan memberikan pemahaman kepada guru tentang pentingnya bahan ajar berbasis digital, pengenalan aplikasi Classroom sebagai sarana digitalisasi bahan ajar, dan pengemasan bahan ajar melalui Classroom. Guru tampak sangat antusisas mengikuti pelatihan. Karena pelatihan langsung diikuti dengan praktik. Kegiatan pelatihan dilanjutkan dengan kegiatan pendampingan. Pendampingan ini dilakukan untuk mengoptimalkan pengoperasian Classroom serta membantu kendala yang dialami guru dalam menggunakan Classroom. Kegiatan pendampingan melibatkan mahasiswa yang sedang magang di sekolah tersebut. Pengemasan bahan ajar melalui Classroom dapat dilakukan melalui laptop maupun android. Berikut ini dipaparkan langkah-langkah mengoperasikan Classroom (melalui computer) pada saat pelatihan berlangsung.

1. Buka classroom.google.com

2. Mulai membuat kelas dengan klik tambahkan (+) lalu Buat Kelas. Masukkan nama kelas (wajib), bagian (boleh diisi jadwal atau detail lainnya), nama ruang dan nama mata pelajaran (pilihan). 


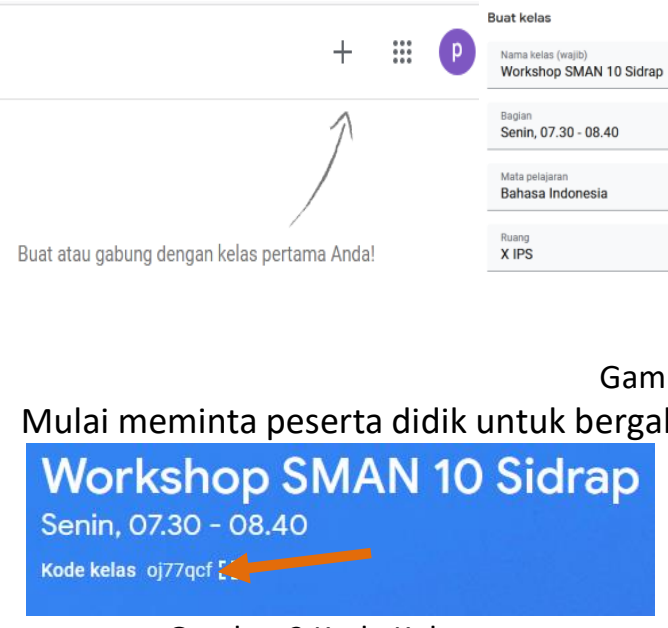

Gambar 2 Kode Kelas

4. Mulai menambahkan materi ke halaman tugas kelas

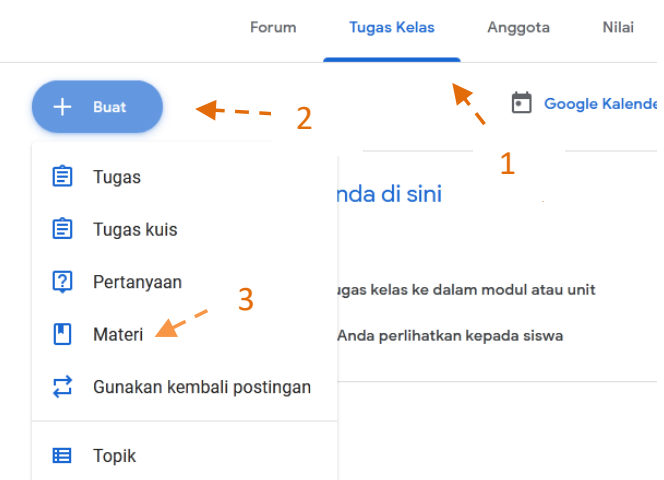

Gambar 3 Menambahkan Materi

5. Mulai mengirim tugas, tugas kuis, atau pertanyaan pada halaman tugas kelas

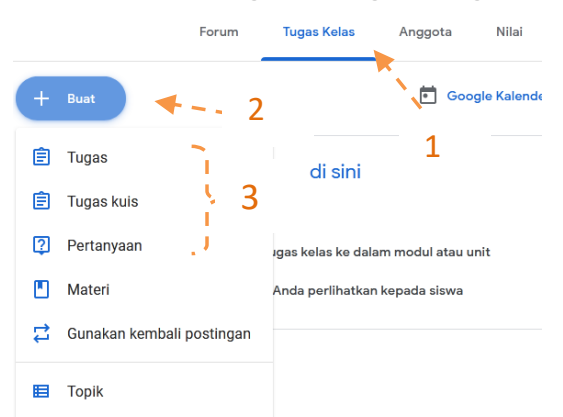

$\times$ Tugas

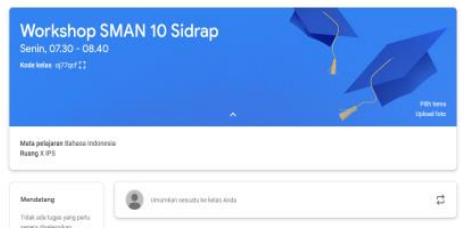

Batal Buat

ambar 1 Buat Kelas

3. Mulai meminta peserta didik untuk bergabung ke kelas dengan membagikan kode kelas.

Workshop SMAN 10 Sidrap

Senin, $07.30-08.40$

Forum Tugas Kelas Anggota Nila

Gambar 4 Mengirim Tugas

6. Mulai mengecek tugas, memberi nilai, dan mengembalikan tugas kelas

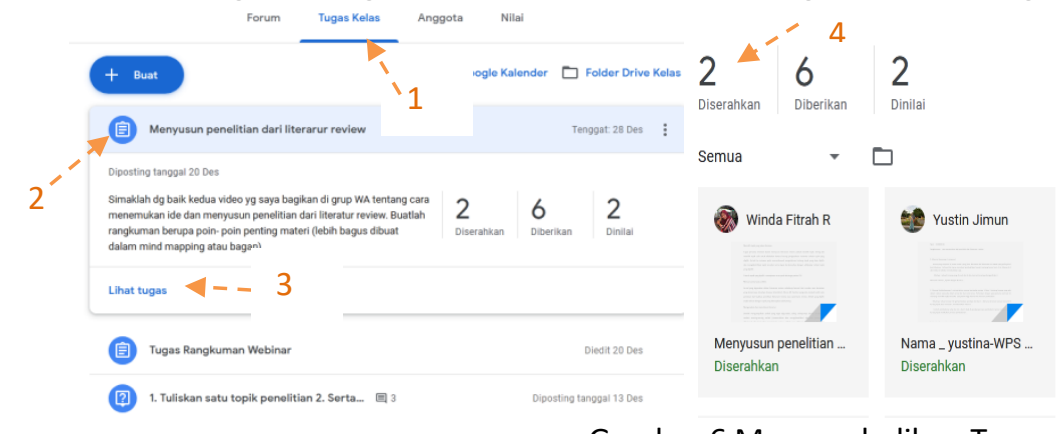

Gambar 6 Mengembalikan Tugas

7. Mulai merekap tugas dan nilai pada halaman nilai

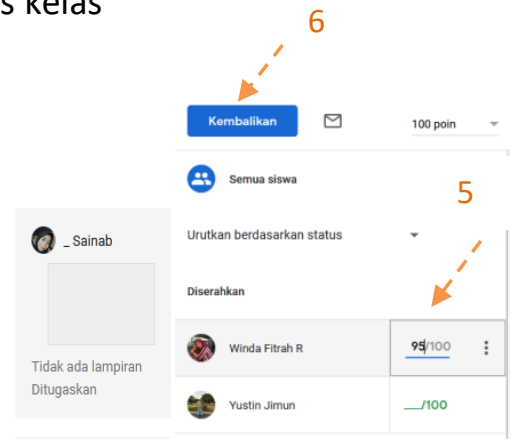




\section{4 | MALLOMO: Journal of Community Service}

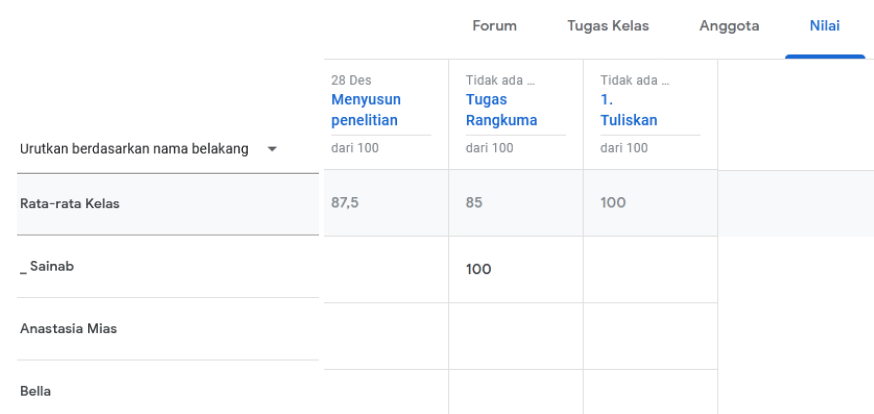

Gambar 7 Merekap Nilai

\section{c. Evaluasi}

Evaluasi ini dilakukan setelah kegiatan pendampingan selesai. Hal ini bertujuan untuk mengukur kemampuan guru setelah mengikuti pelatihan dan pendampingan. Melalui evaluasi ini diketahui bahwa guru telah mampu membuat bahan ajar berbasis digital melalui Classroom. Bahan ajar ini dapat digunakan untuk melatih kemandirian peserta didik dalam belajar. Walaupun demikian, peran guru di kelas tetap dibutuhkan untuk menjaga dan meningkatkan motivasi belajar sehingga kondisi belajar tetap optimal (Manizar, 2015). Selain itu, kegiatan ini juga menghasilkan handout tentang panduan praktis menggunakan Clasroom. Handout ini dapat membantu guru dalam mengoperasikan Classroom kapan saja. Sehingga penggunaan Classroom tetap berkelanjutan.

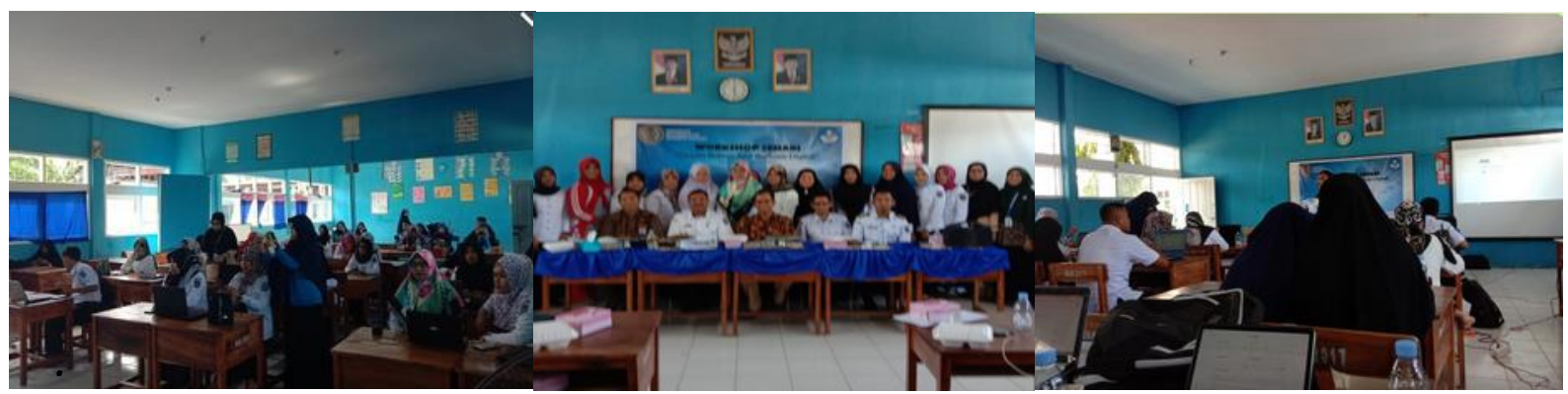

Gambar 8 Pelaksanaan Kegiatan Pelatihan

\section{Simpulan Dan Saran}

Berdasarkan pelaksanaan kegiatan ini penulis menyimpulkan bahwa melalui pelatihan dan pendampingan ini, guru telah mampu mendesain bahan ajar berbasis digital dengan bantuan Aplikasi Classroom. Handout yang berisi panduan praktis menggunakan Classroom diharapkan dapat mendampingi guru setiap saat jika dibutuhkan. Oleh karena itu, diharapkan agar aplikasi ini dapat dioptimalkan pemanfaatannya. Selain itu, kegiatan ini juga diharapkan dapat menjadi ajang kerja sama lanjutan dalam implementasi teori dan penyelesaian fenomena pembelajaran di lapangan.

\section{Daftar Rujukan}

Alperi, M. (2020). Peran Bahan Ajar Digital Sigil Dalam Mempersiapkan Kemandirian Belajar Peserta Didik. Jurnal Teknodik, (1), 99-110.

Azhar, K. A., \& Iqbal, N. (2018). Effectiveness of Google classroom: Teachers' perceptions. Prizren Social Science Journal. 2(2), 52-66. 
Daryanto. (2012). Media Pembelajaran. Bandung: PT Sarana Tutorial Nurani Sejahtera (SATUNUSA). Faisal, M., dkk. (2020). Peningkatan Kompetensi Guru Sekolah Dasar dalam Mengembangkan Bahan Ajar Digital di Kabupaten Gowa. Publikasi Pendidikan, 10 (3), 266-270.

Hamid, Moh. Sholeh. (2011). Metode Edutainment: Menjadikan Siswa Kreatif dan Nyaman di Kelas. Yogyakarta: Diva Press.

Kurniawan, B., \& Purnomo, A. (2020). Penggunaan Aplikasi Google Classroom Sebagai Upaya Peningkatan Pembelajaran Online Bagi Guru Matapelajaran IPS. International Journal of Community Service Learning, 4(1), 1-9.

Manizar, E. (2015). Peran guru sebagai motivator dalam belajar. Tadrib, 1(2), 204-222.

Prastowo, Andi. 2013. Panduan Kreatif membuat Bahan Ajar Inovatif, MenciptakanMetode Pembelajaran yang Menarik dan Menyenangkan. Yogyakarta: Diva Press.

Sa'bani, F. (2017). Peningkatan kompetensi guru dalam menyusun RPP melalui kegiatan pelatihan pada MTs Muhammadiyah Wonosari. Jurnal Pendidikan Madrasah, 2(1), 13-22.

Sundari, F. (2017). Peran Guru Sebagai Pembelajar dalam Memotivasi Peserta Didik Usia SD. Prosiding Diskusi Panel Pendidikan "Menjadi Guru Pembelajar" (pp. 60-65). Jakarta: Keluarga Alumni Universitas Indraprasta PGRI.

Yaumi, M. (2018). Media dan Teknologi Pembelajaran. Jakarta: Prenada Media Grup.

Zuriah, N., Sunaryo, H., \& Yusuf, N. (2016). IbM Guru dalam Pengembangan Bahan Ajar Kreatif Inovatif berbasis Potensi Lokal. Jurnal Dedikasi, 13, 39-49. 